\title{
Human factors engineering in computerized mental health care delivery
}

\author{
JAMES H. JOHNSON, STEVE W. GODIN, and MICHAEL L. BLOOMQUIST \\ Illinois Institute of Technology, Chicago, Illinois 60616
}

\begin{abstract}
There has been strong clinical resistance to the use of automation in mental health. At least part of the resistance may be due to the researcher's failure to understand the psychological factors involved in the human-computer relationship. This paper reviews human factors research as it may be related to computerized systems in mental health. Human factors considerations are specifically applied to: design and implementation of computer systems, patient-computer interaction, mental health staff-computer interaction, and computer output.
\end{abstract}

There has been a significant increase in the usage of computer technology in mental health care settings (Sidowski, Johnson, \& Williams, 1980). However, difficulties involved in designing and successfully implementing computerized systems remain. The many different approaches to the design and implementation of systems (e.g., Altman, Evenson, Hedlund, \& Cho, 1978; Glueck, 1974; Johnson \& Williams, 1975; Laska \& Bank, 1975) continue to be plagued by problems of clinical and administrative acceptance (Hedlund, Vieweg, Cho, Evenson, Hickman, Holland, Vogt, Wolf, \& Wood, Note 1). A comprehensive framework to guide a psychologist in designing such a system remains to be developed (Giannetti \& Klingler, 1980).

Several attempts have been made to develop human factors guidelines for computer software design (e.g., Schneiderman, 1980; Engel \& Granda, Note 2; Pew \& Rollins, Note 3; Newman, Note 4; Ramsey \& Atwood, Note 5). However, this work has not been addressed to the problems of computer usage in the mental health field.

Because there is a lack of integration between human factors engineering and the utilization of computers in mental health, in this paper we will review some relevant human factors research and suggest how this work might be applied to some of the common problems found when using computer technology in the mental health field. These problem areas include: design and implementation of computer systems, patient-computer interaction, mental health staff/computer interaction, and computer output. It is hoped that this paper will help make researchers aware of some of the relevant issues and, thus, assist in bringing about needed design improvements that will lead to better acceptance by clinicians and administrators.

Requests for reprints should be sent to James H. Johnson, Department of Psychology, Illinois Institute of Technology, Chicago, Illinois 60616.

\section{HUMAN FACTORS IN THE DESIGN AND IMPLEMENTATION OF COMPUTERIZED SYSTEMS}

There are many factors that must be considered when designing a computerized mental health system. Before designing the system, one should first consult the professional literature about other similar systems. For example, several design guidelines for computerized sys. tems have been developed that can be applied to mental health (e.g., Gaines \& Facey, 1975; Hansen, 1971; Schneiderman, 1980; Wasserman, 1973; Pew \& Rollins, Note 3 ). In addition, research literature in the fields of computer science, human factors engineering, and the behavioral sciences will be useful.

It is imperative to first consider the needs of those who will be using the system. The design for the interactive aspects of the system depends greatly on the users' experiences and abilities. What is appropriate for a naive user is not appropriate for an experienced user. Thus, any system's design needs to include features specifically related to the characteristics of the setting.

An acceptable system should be not only simple, but also powerful, flexible, and low in complexity (Ramsey \& Atwood, Note 5). "Power" is the measure of the amount of work of a single user command. Powerful commands can accomplish an operation that would take multiple commands in a less powerful system and enable the user to more easily accomplish his/her tasks. "Flexibility" is the degree to which a system allows a user to accomplish a given function. A system with high flexibility provides numerous methods (i.e., types of commands) in which a user can accomplish a given function and facilitates user satisfaction. However, increasing flexibility also tends to increase system complexity (Stewart, 1976). To solve this problem, "low-complexity" systems should be developed that use few commands or that partition the commands so that only a small set can be used at any given time. When designing a system, these three factors need to be con- 
sidered simultaneously to reach a balance that best fits the demands of the mental health staff.

Acceptance can also be improved through a design that allows the user to feel in control (Schneiderman, 1980). One way to achieve this is by designing a system that responds to input as rapidly as possible. However, care should be taken to avoid too fast a response time. Franklin and Dean (1974) described reactions to a system characterized by very fast response times. Users reported that the system was easy to use, but they tended to avoid it due to the system's intimidating fast response time. The time lapse between input and output should be a function of the perceived difficulty of the task involved.

Another means to facilitate user control is to implement feedback systems that indicate whether input was fed into the computer correctly. One feedback system that can be applied is the use of a speech-generation system. Such systems programs provide auditory feedback about input (Schneiderman, 1980; Walther \& O’Neil, 1974; Carlisle, Note 6).

It is desirable that systems be able to detect an ambiguity when it occurs. For example, Plath (Note 7) and Codd (Note 8) designed systems that resolve input ambiguity by presenting a list of possible interpretations of the erroneous input from which the user selects one.

If there is an input error, the system should provide constructive and supportive messages about how to correct the error and eliminate similar errors in the future. "Help commands" of tutorial aids should always be available to guide successful interaction (Goodwin, Note 9). Rouse (1977) suggests a system design in which the user determines the amount of instruction required. It is even better if the system is capable of detecting the user difficulties (i.e., consistent input errors) and is programmed to assist in learning the correct procedures.

Another way of decreasing user difficulty is to reduce the amount of information needed to learn and remember while interacting with the computer. Ways in which designers can minimize information load are: (1) selection of an interactive mode that reduces information processing, such as computer-initiated dialogue or command language with appropriate complexity; (2) designing interactive modes with appropriate power (Schneiderman, 1980); and (3) use of mnemonic variable command names (Newsted \& Wynne, 1976).

A good system contains software monitoring probes that provide statistics about user performance and the amount of errors made in certain situations. These data can be used to make positive changes as experience in use is obtained.

All systems should be constructed so that it is difficult to make costly mistakes (i.e., losing data storage on a patient). Errors can also be reduced by making use of available research in keyboard design. For example, Hirsch (1976) determined the error rates for various keys on the keyboard. More directly, specifically designed "keypads" may help reduce errors for those who are inexperienced in typing. However, this approach may cause problems for those individuals who have previous experience with standardized keyboards. The use of alternative keyboards for the various types of users has been proposed to correct this problem (Schneiderman, 1980).

\section{HUMAN FACTORS AND PATIENT- COMPUTER INTERACTION}

It is important to consider the needs and psychological abilities of the individual user. For example, the ability of a distressed patient to concentrate will have a direct effect on the information received, and patient concentration may be interrupted if distracted by the computer's running procedures. Research in human factors engineering can be applied to maximize the quality of patient-computer interactions, thereby facilitating reliable and valid collection of clinical data.

There are several potential problems that could affect patient-computer interaction. Before the patient interacts with the system, it is advantageous to determine if the individual is capable of providing valid responses to the computer. Johnson, Williams, Klingler, and Giannetti (1977) constructed a screening device that quickly assesses the patient's ability to use a computer. When a patient begins to interact with the computer, he/she may have various questions about procedures. Instructions should be easy to understand, with practice situations available prior to actual data gathering. During interaction, patients may be unable to continue with the task. It would be desirable for the system to be able to store the information that has been received. At a more appropriate time, information can then be recalled and procedures can be continued. Some patients have difficulty responding to various questions. The standardization of responses within and across data gathering procedures helps reduce this problem. Many patients have never interacted with terminal keyboards. Thus, the terminal keyboard should be easy to operate with wellspaced keys. The use of specially marked keys (by colors or names) can reduce this type of input error (Cole, Johnson, \& Williams, 1976).

Current research indicates that there are many approaches to inputting information. However, there are only a few that are commonly used and appropriate for the mental health setting. The first is the use of "question-and-answer" data collection. Here, the patient simply responds "yes" or "no" or "true" or "false" to various questions presented (Card, Nicholson, Crean, Watkinson, Evan, Wilson, \& Russell, 1974; Lucas, 1977). Another method of data collection is "form filling." It allows the patient to provide multiple responses in a single transaction and, thus, provides more contextual information (Martin, 1973). Another method of data collection usable in mental health is "menu selection." This procedure allows the patient to choose a response from a list of items (Martin, 1973). Systems designers 
need to clearly understand the characteristics of their patient population before choosing one of these alternatives.

\section{HUMAN FACTORS IN MENTAL HEALTH STAFF/COMPUTER INTERACTION}

To address the problems of staff-computer interaction, it is first necessary to determine the needs of the staff and how a computer may be used to meet these needs. For example, clinical staff need to store and gain access to patient information. Administrative staff need to have access to bookkeeping program evaluation data (Hedlund et al., Note 1). Consequently, the systems design needs to provide a simple means to carry out these tasks.

Most mental health staff members are naive about using computer systems and are in need of a system that is designed to match their inexperience. The systems approach used in patient-computer interaction can also be applied to mental health staff/computer interactions, but mental health staff members need to interact with a computer on a more sophisticated level. Several researchers have pointed out the difficulties involved in designing a system for naive users who need to interact with computers on this more sophisticated level (e.g., Eason, 1976; Eason, Damordaron, \& Stewart, 1975; Stewart, 1974, 1976). Research in human factors engineering can be applied to alleviate these difficulties and maximize the quality of mental health staff/ computer interaction.

One method that is attractive is the use of "computerinitiated dialogue." In this method, the computer presents various alternatives and questions to the user (Martin, 1973; Thompson, 1969, 1971). Examples of this type of dialogue are found in question-and-answer, form-filling, and menu-selection approaches.

There are advantages to using a computer-initiated dialogue in a mental health setting. For example, it decreases the amount of input error because only brief answers such as "true" and "false" are required. In addition, the user need not have extensive knowledge of computer languages. Schneiderman (1980) suggests that, when using computer-initiated dialogue, the designer should take into account term complexity and sequencing to minimize user error.

An advantage of these approaches is the relative ease with which error handling and other user aids can be designed. However, a disadvantage of computer-initiated dialogue is that it constrains the amount of information communicated in a single transaction. Thus, while it may be a desirable mode for inexperienced users, it is often less acceptable for experienced users.

Pew and Rollins (Note 3) suggest using a "dual-mode dialogue." Here, computer-initiated dialogue is available to the naive person and user-initiated dialogue is available to the experienced person. The mode used for naive users is characterized as simple to learn, highly tutorial, and computer initiated. As the naive user gains experience, he/she can begin to take advantage of the computers computational power through the "managerial mode." This mode is characterized as highly abbreviated and user initiated. However, a problem with dual-mode dialogue designs has been the difficulty of designing a transitional phase between the naive mode and the managerial mode. However, the transition can be facilitated through the use of tutorial methods (Ramsey \& Atwood, Note 5). Suggestions for designing command languages are given by Endres (1975), Engel and Granda (Note 2), and Nickerson and Pew (Note 10).

\section{HUMAN FACTORS IN COMPUTER OUTPUT}

The acceptance of computers in mental health care delivery also hinges on the ability of mental health staff to accurately interpret output data. By applying previous research, one can increase the ease of output interpretation. Interpretation of computer output can be augmented through the use of special graphics, summary displays, display formatting, display coding, and hardware factors related to luminance and display flicker (Schneiderman, 1980).

Ramsey and Atwood (Note 5) note that graphic displays make it possible for information to be communicated at high levels of understanding. According to Schneiderman (1980), successful graphic display can limit user boredom and decrease user anxiety or frustration.

In comparing raw data displays with summary displays, Ramsey and Atwood (Note 5) report that better decisions resulted with summary displays. However, these decisions took longer, and users had lower confidence in their decisions.

A significant amount of research has been conducted on human factors related to display formatting. Grether and Baker (1972) and Stewart (1976) have developed guidelines in this area. They emphasize the logical sequencing and presentation of the data in an understandable output format. Ramsey and Atwood (Note 5) suggest that designers should be cautious in determining the number of elements to be displayed on a CRT at any given time. Increasing the number of display elements results in greater amounts of time and numbers of errors in interpretation.

Stewart (1976) and Teichner, Christ, and Corso (1977) report that the use of various techniques in "display coding" can facilitate user understanding and satisfaction. In display coding, one may use alphanumeric coding (language is coded or abbreviated so that displayed words are shortened), color coding (to highlight certain words in crowded displays, for warning signals, or grouping data), brightness coding (the use of various levels of brightness to highlight critical items), spatial coding (information is placed in particular positions to emphasize relationships), shape and size coding (changing various shapes and of the characters to 
express importance), and flashing (used to express urgent or important information). As an example of the importance of coding, Smith and Goodwin (1971) reported a $50 \%$ improvement in a target detection task when target items were flashing.

Gould (1968) reviewed the hardware design factors affecting screen luminance, contrast, and flicker. He suggests that care must be taken to determine optimal levels of office or background luminance to display luminance. User eye strain and fatigue increases with displays that are too bright (Oestberg, 1975; Stocker, 1964). Display flicker can also result in user fatigue and dissatisfaction. Dill and Gould (1970) present guidelines for decreasing flicker through appropriate hardware design.

Another output concern relates to the design of printed reports. Johnson et al. (1977) discuss several approaches to improve acceptance of reports. One method they suggest involves the use of retrofit programming techniques (fitting data from disparate collection procedures backward around key data). This method leads to unified report writing schemes. They also suggest the use of random sentence stems for narrative reports. With this technique, there are at least three alternatives for every sentence to be output. By random selection of one of the choices, each output report is made structurally unique from all others. Other issues to be concerned with in output reporting include: the amount of comprehensive vs. exception reporting, page size, type style, graph usage, and so on. Here again, specific choices are determined by the needs of the user.

\section{DISCUSSION}

Computer systems used in mental health have met with significant resistance. This may be due to the lack of understanding of the human factors involved in the human-computer relationship. In this paper, we have reviewed some of the applications of human factors research appropriate to computer use in mental health care delivery. Increased effort is needed to apply research in human factors to computer usage in mental health. It is our belief that continued work in this area will help lead to improved acceptance in the field.

\section{REFERENCE NOTES}

1. Hedlund J. L., Vieweg, B. W., Cho, D. W., Evenson, R. L., Hickman, C. V., Holland, R. A., Vogt, S. A., Wolf, C. P., \& Wood, J. B. Mental health information systems: $A$ state of the art report (Tech. Rep. UMC-AHCTC-T-001). Columbia, Mo: University of Missouri-Columbia, October 1979.

2. Engel, S. E., \& Granda, R. E. Guidelines for man/display interfaces (Tech. Rep. TR 00.27200). Poughkeepsie, New York: IBM Poughkeepsie Laboratory, December 1975.

3. Pew, R. W., \& Rollins, A. M. Dialgo specification procedures (rev. ed.) (Tech. Rep. 3129). Cambridge, Mass: Bolt Beranek \& Newman, Inc., September 1975.
4. Newman, J. C. User psychology: The experimental strategy. Newton Abbey, Northern Ireland: Ulster College, Northern Ireland Polytechnie, 1977.

5. Ramsey, H. R., \& Atwood, M. E. Human factors in computer systems: $A$ review of the literature (Tech. Rep. SAI-79. 111-DEN) Englewood, Co: Engineering Psychology Programs, Office of Naval Research, September 1979.

6. Carlisle, J. H. Comparing behavior at various computer display consoles in time-shared legal information (Tech. Rep. AD712695) Santa Monica, Calif: Rand Corporation, September 1970.

7. Plath, W. J. Restricted English as a user language. Yorktown Heights, N.Y: IBM Watson Research Center, November 1972.

8. CoDd, E. F. Seven steps to redezvous with the casual user (Tech. Rep. RJ-1333). San Jose, Calif: IBM Research Laboratory, January, 1974.

9. Goodwin, N. C. Intro: In which a smart terminal teaches its own use (Technical Paper MTP-150). Bedford, Mass: MHRE Corporation, March 1974.

10. Nickerson, R. S., \& Pew, R. W. Oblique steps toward the human-factors engineering of interactive computer systems (Tech. Rep. 2190). Cambridge, Mass: Bolt Beranek \& Newman, Inc., 1971.

\section{REFERENCES}

Altman, H., Evenson, R. C., Hedlund, J. I., \& Cho, D. W. The Missouri actuarial report system (MARS). Comprehensive Psychiatry, 1978, 19, 185-192.

Card, W. I., Nicholson, M., Crean, G. P., Watkinson, G., Evans, C. R., Wilson, J., \& Russell, D. A comparison of doctor and computer interrogation of patients. International Journal of Bio-Medical Computing, 1974, 5, 175-187.

Cole, E. B., Johnson, J. H., \& Williams, T. A. When psychiatric patients interact with computer terminals: Problems and solutions. Behavior Research Methods \& Instrumentation, $1976,8,92-94$.

Dill, A. B., \& Gould, J. D. Flickerless regeneration rates for CRT displays as a function of scan order and phosphor persistence. Human Factors, 1970, 12, 465-471.

EAson, K. D. Understanding the naive computer user. Computer Journal, 1976, 19, 3-7.

Eason, K. D., Damordaron, L., \& Stewart, T. F. M. Interface problems in man-computer interaction. In E. Mumford \& H. Sackman (Eds.), Human choice and computers, Amsterdam: North-Holland, 1975.

ENDREs, A. An analysis of errors and their causes in system programs. IEEE Transactions on Software Engineering, 1975, 1, 140-149.

Franklin, J., \& Dean, E. Some expected and not so expected reactions to a computer-aided design with interactive graphic system. SID Journal, 1974, 3, 5-13.

GAINES, B. R., \& FACEY, P. V. Some experience in interactive system development and application. Proceedings of the IEEE, 1975, 63, 894-911.

Giannetti, R. A., \& Klingler, D. E. A conceptual analysis of computerized mental health care systems. In J. B. Sidowski, J. H. Johnson, \& T. A. Williams (Eds.), Technology in mental health care delivery systems. Norwood, N.J: Ablex, 1980.

Guveck, B. L. Computers at the institute of living. In J. F. Crawford, D. W. Morgan, \& D. T. Gianturco (Eds.), Progress in mental health information systems: Computer applications. Cambridge, Mass: Ballinger, 1974.

Grether, W. F., \& B^кEn, C. A. Visual presentation of information. In H. P. Van Cott \& R. G. Kinkade (Eds.), Human engineering guide to equipment design (rev. ed.). Washington, D.C: U.S. Government Printing Office, 1972. 
HANSEN, W. J. User engineering principles for interactive systems, Proceedings of the Fall Joint Computer Conference, 1971, 39, 523-532.

Hinsch, R. S. Human factors in man-computer interfaces. San Jose, Calif: IBM Human Factors Center, 1976.

Johnson, J. H., \& Williams, T. A. The use of on-line computer technology in a mental health admitting system. American Psychologist, 1975, 30, 388-390.

Johnson, J. H., Williams, T. A., Klinglen, D. E., \& GianNE TTI, R. A. Interventional relevance and retrofit programming: Concepts for the improvement of clinician acceptance of computer-generated assessment reports. Behavior Research Methods \& Instrumentation, 1977, 9, 123-132.

LAsKA, E. M., \& BANK, R. Safeguarding psychiatric privacy: Computer systems and their uses. New York: Wiley, 1975.

LucAs, R. W. A study of patients' attitudes to computer interrogation. International Journal of Man-Machine Studies, 1977, 9, 69-86.

Martin, J. Design of man-computer dialogues. Englewood Cliffs, N.J: Prentice-Hall, 1973.

NEwsted, P. R., \& WYnne, B. E. Augmenting man's judgement with interactive computer systems. International Journal of Man-Machine Studies, 1976, 8, 29-59.

OEstberg, 0 . CRTs pose health problems for operations. International Journal of Occupational Health and Safety, 1975, 44, 24-26.

Rouse, W. B. Human-computer interaction in multitask situations. IEEE Transactions on Systems, Man and Cybernetics, 1977, 5, 384-392.

Schneiderman, B. Software psychology: Human factors in computer and information systems. Cambridge, Mass: Winthrop, 1980.

Sidowskı, J. B., Johnson, J. H., \& Williams, T. A. (Eds), Technology in mental health care delivery systems. Norwood, N.J: Ablex, 1980.

Smith, S. L., \& Goodwin, N. C. Blink coding for information display. Human Factors, 1971, 13, 283-290.

STEWART, T. F. M. Ergonomic aspects of man-computer problem solving. Applied Ergonomics, 1974, 5, 209-212.

STEWART, T. F. M. Displays and the software interface. Applied Ergonomics, 1976, 7, 137-146.

Stocker, A. C. Displays, papers, and lighting: A visual system in command centers. Information Display, 1964, 1, 16-26.

Teichner, W. H., Christ, R. E., \& Conso, G. M. Color research for visual displays (Report No. ONR-CR213-102-4F). Las Cruces, New Mexico: New Mexico State University, Department of Psychology, June 1977. (NTIS No. AD A043609)

Thompson, D. A. Man-computer system: Toward balanced cooperation in intellectural activities. In Proceedings, International Symposium on Man-Machine Systems, 1969, 1, 57.

Thompson, D. A. Interface design for an interactive information retrieval system: A literature survey and a research system description. Journal of the American Society for Information Science, 1971, 22, 361-373.

Walther, G. H., \& O'Neil, H. F., JR. On-line user-computer interface: The effects of interface flexibility, terminal type, and experience on performance. AFIPS Conference Proceedings, $1974,43,379-384$

Wasserman, A. I. The design of "idiot-proof" interactive programs. AFIPS Conference Proceedings, 1973, 42, M34-M38. 